\title{
Tactile attention and the perception of moving tactile stimuli
}

\author{
PAUL M. EVANS \\ Willamette University, Salem, Oregon \\ and \\ JAMES C. CRAIG \\ Indiana University, Bloomington, Indiana
}

\begin{abstract}
Three experiments investigated the ability of subjects to identify the direction of movement of a pattern across the skin. In Experiments 1 and 2, subjects were required to identify the direction of movement of a pattern presented to one fingerpad while another moving pattern was being presented to an adjacent fingerpad. Subjects were instructed to attend only to the target location. The results showed that accuracy was consistently higher and reaction times were consistently faster when the two patterns moved in the same direction than when they moved in opposite directions. Both effects were largest when the two patterns were presented simultaneously. In Experiment 3, the nontarget location was the contralateral hand. In this case, performance was not affected by the presentation of the nontarget. Combined, the results suggest that movement information is processed across adjacent fingers even when subjects are explicitly instructed to attend only to one finger. Subjects do appear to be able to restrict attention to a single hand.
\end{abstract}

Common experience tells us that when examining textured surfaces by touch, we typically run two or more fingers across each surface. Also, when exploring an object haptically, such as feeling for a specific coin or key in one's pocket, the object is manipulated between two or more fingers at the same time. Haptic exploration of surfaces and objects with the hand is usually extended over time and space, and often a number of sites on the fingers are stimulated simultaneously.

The fact that haptic surface and object exploration typically involves contact with a number of sites on the fingers at a time suggests that when we are discriminating between textured surfaces, or when we are attempting to identify an object by touch alone, we combine information obtained from different fingers. Perhaps one of the most dramatic examples of this ability is provided by users of the Tadoma method of speech communication. By placing their fingers against the jaw, lips, and throat of a speaker, some deaf-blind individuals have been trained to understand speech by feeling the articulatory gestures produced by the speaker. Combining information from the fingers enables Tadoma users to comprehend lownormal rates of speech (Reed, Durlach, \& Braida, 1982).

This research was supported by Grant DC-00095 from the National Institutes of Health and by Grant $90-0215$ from the Air Force Office of Scientific Research. The research was conducted while the first author was a Visiting Scholar at the Institute for the Study of Human Capabilities, Indiana University. The authors thank Roger P. Rhodes for his assistance in conducting these experiments. Reprint requests should be addressed to Paul M. Evans, Department of Psychology, Willamette University, Salem, OR 97301.
There have been a number of empirical investigations of our ability to combine information presented to multiple sites on the skin. For example, Geldard and Sherrick (1965) investigated the ability of subjects to discriminate between patterns generated by stimulating sites widely distributed across the body surface. In brief, subjects had relatively little difficulty in determining whether the same or different sites on the skin had been stimulated even though each pattern could consist of up to nine vibrators (also see Cholewiak \& Craig, 1984; Gilson, 1969). More recently, Craig (1985a) investigated the ability of subjects to identify spatial tactile patterns that were split between two fingers. Using the tactile display of the Optacon (Bliss, Katcher, Rogers, \& Shepard, 1970), half of a spatial pattern was presented to the left index fingerpad, and the other half was presented to the left middle fingerpad. Both halves were presented at the same time. The task was to combine the two pattern halves and respond with the complete pattern. Although performance was better when the entire pattern was presented to a single fingerpad, subjects were able to combine the two pattern halves and correctly identify the patterns significantly better than chance. These results, and the success of the Tadoma method of speech communication, attest to the fact that we can process information from two (or more) skin sites even when the sites are stimulated simultaneously.

In the studies described above, it was necessary for subjects to attend to more than one site of stimulation at a time. Common experience also tells us, however, that when we are focusing our attention on one site on the skin, stimulation at another site (e.g., a tap on the shoulder or a mosquito bite on the arm) may capture our attention. 
Indeed, a number of studies have demonstrated that stimulation at a nontarget location can interfere with the ability to detect a stimulus at a target location even though subjects are explicitly instructed to attend only to the target site (e.g., Craig, 1974; Gilson, 1969; Sherrick, 1964). In general, interference declines as the spatial distance between the target and nontarget locations increases, although contralaterally placed maskers may still cause significant amounts of interference (Sherrick \& Cholewiak, 1986).

In addition to detection masking, the ability to identify a spatial tactile pattern is interfered with if a nontarget pattern is presented to a different site. Using the tactile display of the Optacon, Weisenberger (1981) presented target patterns to the upper portion of the left index fingerpad; other, nontarget, patterns were presented to the lower portion of the same fingerpad. When the temporal separation between the onsets of the two patterns (stimulus onset asynchrony or SOA) was brief, pattern identification was significantly worse than it was in the absence of the nontarget pattern. As with detection masking, increasing the spatial separation between targets and nontargets (by presenting them to different fingers) leads to a reduction in the amount of interference at a given SOA (Craig, 1985b).

The fact that a pattern presented at one location on the skin can interfere with the ability to identify a pattern presented at another location means that, even when subjects are instructed to attend only to the target site, the pattern at the nontarget site must be registered. It is possible that a pattern at a nontarget location simply captures our attention and distracts us. Detecting that another pattern has been presented may momentarily draw attention away from the target site, perturb the perceptual process, and lead to a decrease in the ability to identify (or detect) a target. Also, the fact that subjects can combine information from a number of sites of stimulation on the skin simultaneously does not preclude the possibility that subjects are, in fact, processing information from one site and then switching their attention quickly to a second site, a third site, and so forth. Alternatively, it is possible that subjects are unable to restrict attention to a single location on the skin. The spotlight of attention on the skin may be quite broad. As a consequence, some attributes of a nontarget pattern may be processed and may interfere with the ability to identify a target pattern.

In the present study, we investigated the ability of subjects to identify the direction of movement of a pattern across the skin in the presence of another moving pattern presented at an adjacent fingerpad. We selected direction of motion across the skin as the stimulus dimension to be examined for two major reasons. First, movement appears to be a significant component of tactual experience. It is an important stimulus dimension in its own right and plays a major role in haptic exploration. Second, there has been considerable neurophysiological investigation of movement on the skin. This research has revealed movement-sensitive neurons in primary somatosensory (SI) cortex of monkeys (see Costanzo \& Gardner, 1980; Gard- ner, 1984; Gardner, Hamalainen, Palmer, \& Warren, 1989; Gardner \& Palmer, 1989, 1990; Morley \& Goodwin, 1987; Warren, Hamalainen, \& Gardner, 1986; Whitsel, Roppolo, \& Werner, 1972). Several of these studies (e.g., Gardner \& Palmer, 1990) have found direction-sensitive neurons, suggesting that direction of movement may be registered in a relatively automatic fashion, that is, without focused attention. If the direction of movement of a tactile pattern is registered automatically, then subjects may experience difficulty identifying the direction of movement of a pattern at a target (attended) location when its direction conflicts with that of a pattern presented to a nontarget (nonattended) location. If this result is obtained, then it would imply not only that subjects cannot restrict processing to a single location on the skin, but also that stimulation at a nontarget location does more than merely draw attention away from the target site.

A recent study by Essick and Whitsel (1988) provides preliminary evidence that subjects cannot restrict attention (or processing) to a single site on the skin and that information about the direction of movement at a nontarget location is processed. They investigated the ability of subjects to identify the direction of a brushing motion applied to the dorsal side of the hand. A second moving stimulus was applied to one of several locations: ipsilateral forearm, ipsilateral shoulder, contralateral shoulder, or contralateral hand. In one condition, subjects were instructed to focus their attention only on the target location on the left hand and to ignore the stimulus applied to the second location. The stimulus at the nontarget site moved either in the same direction as the target or in the opposite direction. In addition, the nontarget stimulus was presented at approximately the same time as the target stimulus or with some temporal interval between the two stimuli. In the majority of conditions, the nontarget stimulus did not affect the accuracy of identification of the direction of movement at the target site. There were some conditions, however, in which the nontarget did interfere with target performance, a finding that suggests that movement at a nonattended site may be processed in an automatic fashion without focused attention. These results will be considered in more detail in the course of discussing the results of the present study.

\section{EXPERIMENT 1}

In Experiment 1, we investigated the ability of subjects to identify the direction of a moving stimulus at one fingerpad while attempting to ignore a moving nontarget stimulus presented to an adjacent fingerpad. Accuracy and response latencies were measured. Both the target and the nontarget were vertical bar-like patterns generated on the tactile array of the Optacon. The pattern presented to the target site, the left index fingerpad, moved across the fingerpad from left to right or from right to left. Similarly, the pattern presented to the nontarget location, the left middle fingerpad, also moved. On half of the trials, the nontarget pattern moved in the same direction as the 
target pattern (compatible-movement condition); on the other half of the trials, it moved in the opposite direction (incompatible-movement condition). The temporal separation between the onsets of the two patterns (SOA) was varied. The nontarget pattern was presented at the same time as the target or preceded the onset of the target by a variable delay.

If the effect of stimulation at a nonattended site is simply to draw attention away from the target location (and momentarily perturb the perceptual process), then performance should be worse at the briefest SOAs and improve as the SOA is increased. More importantly, the direction of movement of the nontarget pattern should not influence performance differentially. If, however, subjects are unable to restrict processing to a single fingerpad, and if information about the direction of movement of both patterns is processed simultaneously across adjacent fingers, then the direction of movement of the nontarget relative to that of the target may affect performance in a systematic fashion. Specifically, responses may be faster and more accurate when both patterns move in the same direction than when they move in opposite directions, especially when the nontarget and the target are presented close together in time.

\section{Method}

Subjects. The subjects in this study were drawn from a pool of 8 undergraduate students at Indiana University, who were paid employees of the laboratory, and the first author. All were experienced subjects who had completed a number of related experiments prior to participating in the present study. Six subjects participated in Experiment 1.

Apparatus. The apparatus consisted of two tactile arrays interfaced to a PDP 11/34 computer. Each tactile display was identical to that used in the Optacon (Telesensory Systems, Inc.), and each consisted of 144 pins arranged in a rectangular array measuring $11 \mathrm{~mm}$ wide and $27 \mathrm{~mm}$ high. There were six columns and 24 rows of pins. Adjacent columns were separated by $2.3 \mathrm{~mm}$; adjacent rows were separated by $1.2 \mathrm{~mm}$. When activated, the pins on the display vibrated at a frequency of approximately $230 \mathrm{~Hz}$. The computer enabled spatial patterns to be generated on the tactile arrays for durations that were multiples of $4.35 \mathrm{msec}$. In addition to controlling the tactile arrays, the computer controlled a visual display (used for instructions and feedback) and the presentation routine, and it collected the subjects' responses and response latencies. More detailed information about the apparatus can be found in Craig (1980).

Stimuli. Movement on each fingerpad was simulated by shifting the location of activated pins in a column-by-column sequence. For example, to simulate movement across each fingerpad from left to right, column 1 of the tactile display was activated for $8.7 \mathrm{msec}$, followed by the activation of column 2 for $8.7 \mathrm{msec}$, and so on. Pilot work was conducted to set the stimulus conditions to produce the sensation of movement. Activating each column for the minimum duration possible, $4.35 \mathrm{msec}$, resulted in a very "light" sensation. Increasing the duration of activation for each column produced a much clearer experience of continuous movement, as results using two points on the fingerpad would predict (Kirman, 1974). It was decided to keep the total stimulus duration as brief as possible and still produce movement of reasonable quality. The stimulus duration of $8.7 \mathrm{msec}$ per column was selected because it produced good movement while keeping the overall duration relatively brief (total duration $\approx 52 \mathrm{msec}, 6$ columns $\times 8.7 \mathrm{msec} /$ column). The voltage to the stimulators was set at $36 \mathrm{~V}$. The subjects reported that the displays produced a comfortable level of stimulation, well above threshold, and that they perceived continuous motion, although some subjects reported that the quality of the motion differed somewhat at the index and middle fingerpads.

Procedure. Each subject was tested with the left arm extended and with the left index fingerpad resting on one tactile array and the left middle fingerpad resting on the second tactile array. The subject responded with the index and middle fingers of the right hand, which was resting on a standard keyboard.

The subject was told that he/she would be presented with tactile patterns to the left index and left middle fingerpads and that the patterns would appear to be moving. He/she was instructed to focus attention on the left index fingerpad and to report the direction of movement on that finger. The subject was explicitly instructed to ignore the stimulation on the left middle fingerpad. Accuracy was stressed, although the subject was asked to respond as quickly as possible. The subject was told that responses were being timed.

The subject initiated a trial by pressing either one of the response buttons. One second later, a moving pattern was presented to the left middle fingerpad, the nontarget site. A moving pattern was also presented to the left index fingerpad, the target site, either simultaneously with the onset of the nontarget or after a variable delay. The time between the onsets of the two patterns (SOA) was 0,100 , 300 , or $500 \mathrm{msec}$. Following the presentation of the two patterns, the subject responded by pressing one of two buttons on the keyboard. A correct response was followed by the word coRRECT appearing on the visual display for $500 \mathrm{msec}$. An incorrect response was followed by the word WRONG appearing on the visual display for $500 \mathrm{msec}$. The visual display then went blank. By pressing either of the response buttons, the subject could then initiate the next trial. The subject wore earphones through which white noise was presented to eliminate auditory cues produced by the tactile arrays.

Each session consisted of eight blocks of 32 trials. The temporal separation between the onsets of the two patterns was varied on a trial-by-trial basis. Within each session, an equal number of trials were presented at each SOA value. On half of the trials, the two patterns moved in the same direction; on the other half of the trials, the two patterns moved in different directions. Each session lasted approximately $30 \mathrm{~min}$. Each subject completed one session per day for a total of five sessions.

\section{Results and Discussion}

Accuracy. Figure 1 shows the percentage of correct responses, averaged across subjects, for each trial type as a function of SOA. The results of a two-way, repeated measures analysis of variance revealed a main effect of $\operatorname{SOA}[F(3,15)=6.55, p<.005]$, no main effect of trial

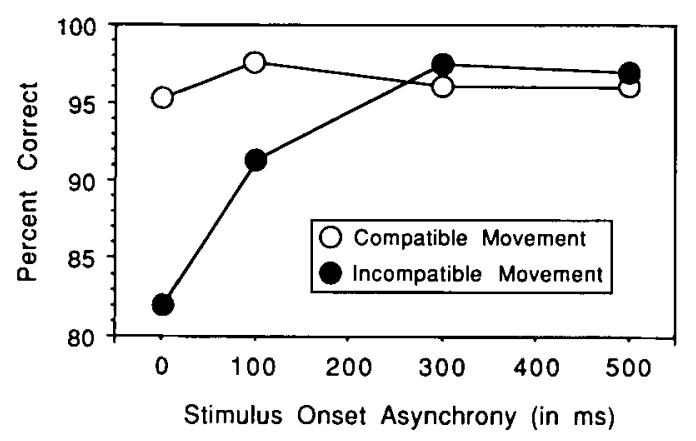

Figure 1. Percent correct movement identification for compatiblemovement and incompatible-movement trials as a function of the time between the target stimulus and the nontarget stimulus (SOA). 
type $[F(1,5)=6.47, p>.05]$, and an interaction between SOA and trial type $[F(3,15)=10.19, p<.001]$. The interaction effect can be seen in Figure 1. When the nontarget moved in the same direction as the target, performance was consistently high and did not vary as a function of SOA (average performance $=96 \%$ ). When the nontarget and the target moved in opposite directions, performance was worse at the briefest SOA (82\%) and improved as the SOA was increased $(96 \%$ at $500-\mathrm{msec}$ SOA). Post hoc comparisons (Tukey HSD method) showed that performance was worse at 0-msec SOA when the nontarget and the target moved in opposite directions than when the nontarget and the target moved in the same direction (82\% vs. $95 \%$ ). Beyond 0-msec SOA, performance was statistically equivalent for both trial types.

Reaction times. Mean reaction times were calculated for correct responses and averaged across subjects. An analysis of variance showed a main effect of SOA $[F(3,15)$ $=13.11, p<.0005]$, a main effect of trial type $[F(1,5)=$ $21.01, p<.01]$, and no interaction between these two factors $[F(3,15)=1.70, p>.05]$. The results are shown in Figure 2. Averaged across the two trial types, reaction times were slowest at the briefest SOAs. The average reaction time was $459 \mathrm{msec}$ at $0-\mathrm{msec}$ SOA, and $380 \mathrm{msec}$ at 500-msec SOA (a difference of $79 \mathrm{msec}$ ). Overall, however, responses were faster in the compatible-movement condition than in the incompatible-movement condition. On the average, correct responses were $23 \mathrm{msec}$ faster when the nontarget and target moved in the same direction than when they moved in opposite directions. The difference between response latencies for the two trial types was largest at the briefest SOA (43 $\mathrm{msec}$ at 0 -msec SOA) and decreased as the SOA was increased $(8 \mathrm{msec}$ at 500-msec SOA).

As noted earlier, Essick and Whitsel (1988) examined the effect of movement at one of four nontarget sites on the identification of movement on the dorsal side of the hand. In one set of measurements, the target and nontarget stimuli were presented at approximately the same time (the onsets were within $20 \mathrm{msec}$ of each other), roughly

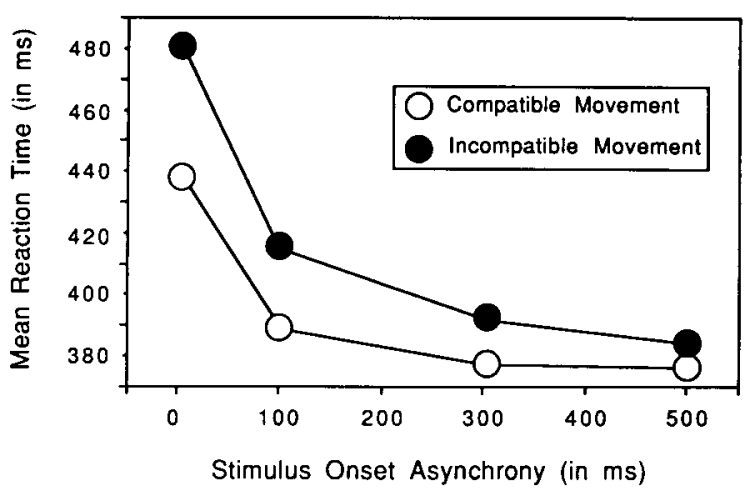

Figure 2. Mean latency (correct trials) for compatible- and incompatible-movement trials as a function of the time between the target stimulus and nontarget stimulus. comparable to the $0-\mathrm{msec}$ SOA in the present study. For one of the eight simultaneous conditions, the nontarget stimulus had a significant effect on performance at the target location. Specifically, when the nontarget stimulus was presented to the ipsilateral shoulder, incompatible movement produced a significant decline in identification performance relative to target performance in the absence of stimulation at a nontarget location. In a second set of measurements, Essick and Whitsel (1988) introduced a temporal delay of $150 \mathrm{msec}$ between the onsets of the target and nontarget stimuli. Here, in four of the eight conditions, they found a significant decline in performance at the target location relative to single-pattern performance.

Essick and Whitsel (1988) attributed their finding of greater interference when the nontarget and target were presented sequentially to the generation of apparent motion cues between the two locations (Kirman, 1983; Sherrick, 1968; Sherrick \& Rogers, 1966). They hypothesized that the generation of apparent motion between the target and nontarget locations overwhelmed the local motion produced at the target site. It is unlikely that apparent motion between the two fingers was a major factor affecting the present results. First, the times between onsets of the stimuli delivered to the two fingers were not ideal for generating apparent motion (Sherrick \& Rogers, 1966). Second, in contrast to the subjects in the Essick and Whitsel study, our subjects did not report apparent motion between the two fingers. Nevertheless, we analyzed the results to see if performance was affected by apparent motion cues. If subjects use such cues, then performance should be considerably better when the direction of apparent motion is in the same direction as the local movement on the target fingerpad. If subjects rely solely on apparent motion cues, performance should be less than chance when the target moves in the direction opposite to that signalled by the apparent motion. Indeed, in the study by Essick and Whitsel (1988), subjects often did perform below chance level when the target direction and apparent motion cues were in conflict. We were particularly concerned with the nonzero SOAs where apparent motion might be generated. Our analysis showed that at only one of the three nonzero SOAs, $100 \mathrm{msec}$, was overall performance better when the target moved in the direction consistent with apparent motion cues $(98 \%)$ than when the target moved in the opposite direction (91\%). At 300and 500-msec SOAs, performance for the two targets was essentially equivalent (less than $1 \%$ difference between directions of movement). Finding only a small difference in performance favoring the direction of apparent motion, coupled with the fact that the subjects performed well above chance in all conditions, suggests that, as expected, apparent motion cues were not particularly compelling in the present experiment.

For both compatible- and incompatible-movement trials, reaction times decreased as the SOA was increased. This effect may have been the result of a general alerting reaction (Posner \& Boies, 1971); that is, the onset of the 
pattern at the nontarget location may have acted as a warning signal enabling the subjects to prepare for the arrival of the target. A number of studies in the visual literature have shown that providing subjects with a signal before the onset of a target reduces reaction times (Bertelson, 1967; Posner \& Boies, 1971) and improves signal detectability (Egan, Greenberg, \& Schulman, 1961). In general, performance is worse with no warning signal and is best if a warning signal precedes the onset of a target by 200 to 500 msec (Posner, 1980; Posner \& Boies, 1971). Studies that have investigated the effect of a warning signal on the time taken to identify a target, or on the ability to detect a target, have typically used blocks of trials with a fixed warning interval to reduce uncertainty about when the target will occur. In the present experiment, the time between the onsets of the nontarget and target varied on a trial-by-trial basis and thus provided no information as to when the target would occur. It is possible, however, that the onset of the nontarget pattern acted as a warning signal on those trials when the SOA was not zero.

The results of Experiment 1 show that accuracy was higher and that response latencies were faster when the nontarget and the target moved in the same direction across the skin than when they moved in opposite directions. One explanation of these findings is that information about the direction of movement across adjacent fingers is processed even when subjects are instructed to attend only to the target location. The results suggest that subjects cannot restrict processing to a single location on the skin. Alternatively, it could be argued that subjects are able to restrict processing to a single location on the skin but, on occasion, focus their attention on the wrong (nontarget) location and respond with the nontarget. This explanation would account for the accuracy data. On the trials when the nontarget and the target moved in the same direction, attending to the wrong location would lead to a correct response. When the nontarget and the target moved in opposite directions, attending to the wrong location would lead to an incorrect response. Thus, on the average, accuracy in the compatible-movement condition would be higher than that in the incompatible-movement condition.

Attending to the nontarget location, the middle fingerpad, would also lead to faster reaction times in the compatible-movement condition than in the incompatiblemovement condition, if the additional assumption is made that patterns are processed faster on the middle finger than on the index finger. Relatively fast reaction times to patterns presented to the middle fingerpad would decrease the average time to respond in the compatible-movement condition but not in the incompatible-movement condition. In the incompatible-movement condition, attending to the nontarget location would, of course, lead to an incorrect response.

The evidence suggests that the subjects were not simply attending, on occasion, to the wrong location. At 0 -msec SOA, the subjects erred $18 \%$ of the time on incompatible-movement trials. If the subjects erred be- cause they were attending to the nontarget site, and if patterns are processed faster on the middle than on the index fingerpad, then we would expect reaction times on these error trials to be particularly fast. They were not. In fact, reaction times for incorrect responses (incompatible trials) were slower than reaction times for correct responses (for either incompatible or compatible trials). The results suggest that incompatible movement at an adjacent finger interferes with the ability to judge the direction of movement at a target location. The most parsimonious conclusion is that information about the direction of movement at a nontarget location is processed even though subjects are instructed to focus their attention at a different, target location.

\section{EXPERIMENT 2}

In Experiment 2, we expanded upon the findings of Experiment 1 by including an additional type of nontarget stimulus. This stimulus, a nonmoving horizontal bar, was termed a neutral stimulus because it was not one of the target responses. Although the evidence from Experiment 1 did not support the notion that subjects were simply attending, on occasion, to the nontarget site, the presentation of a neutral stimulus would provide additional data pertinent to this issue. If subjects sometimes focus attention on the wrong location, then it follows that they will, on occasion, begin to process the neutral pattern. The fact that this pattern is not available as a response means that subjects could either guess the direction of movement of the target or switch attention quickly to the target site. The first strategy should lead to particularly poor performance with the neutral pattern. The second strategy, switching attention to the target site, should lead to relatively slow reaction times with the neutral pattern, if the plausible assumption is made that switching attention among sites on the skin takes time (Craig, 1985b). Experiment 2 also replicated the conditions of Experiment 1 and thus provided an assessment of the robustness of the observed effects.

Experiment 2 was conducted in two parts. In the first part, the subjects were instructed to respond as quickly and as accurately as possible (as in Experiment 1). Here, we were primarily interested in the pattern of response latencies. In the second part of Experiment 2, we focused on the accuracy of responses. Because performance in the compatible-movement condition of Experiment 1 was close to ceiling $(96 \%)$, overall accuracy was reduced in the second part of Experiment 2 by presenting a masking stimulus immediately after the presentation of the target pattern.

\section{Method}

Five subjects participated in Experiment 2. The experiment was conducted in two parts. The general procedural details for both parts were identical to those of Experiment 1 with the following exceptions. First, only two SOAs were tested, 0- and 500-msec SOAs. Second, an additional trial type was included. On one third of the 
trials, the pattern presented to the nontarget location was a horizontal bar formed by simultaneously activating all pins in rows 8,9 , and 10 of the display for $52 \mathrm{msec}$. On the remaining two thirds of the trials, the nontarget pattern was a vertical bar that moved either in the same direction as the target pattern or in the opposite direction. Third, with the inclusion of the extra trial type, the number of trials was increased from 32 to 48 per block.

In both parts of Experiment 2, the subject's task was, as in Experiment 1 , to focus attention on the left index fingerpad and to identify the direction of movement of the pattern presented to that finger. In the first part, the subject was instructed to respond as quickly and as accurately as possible. In the second part, the subject was told that a masking stimulus would be presented immediately after the presentation of the target. The task was to try to ignore the masker at the same location as the target and to identify the direction of movement of the target as accurately as possible. The masking stimulus consisted of turning on all of the pins of the tactile display for $52 \mathrm{msec}$. This masking stimulus has previously been referred to as an energy masker (Craig, 1982). The SOA between the onset of the target and the onset of the masker was $74 \mathrm{msec}$. Subjects completed the first part of Experiment 2 before beginning the second part. In the first part, each subject participated in eight experimental sessions; in the second part, each subject participated in four sessions.

\section{Results and Discussion}

Accuracy. The results for the first part of Experiment 2 are shown in Figure 3. An analysis of variance revealed no main effect of SOA $[F(1,4)=1.41, p>.05]$, a main effect of trial type $[F(2,8)=7.15, p<.02]$, and an interaction between SOA and trial type $[F(2,8)=6.02$, $p<.05]$. Post hoc comparisons showed that at 0 -msec SOA, performance was lower when the nontarget moved in the opposite direction from the target (88\%) than when it moved in the same direction as the target $(94 \%)$ or did not move (93\%). In the latter two conditions, performance was, as expected, close to ceiling. At $500-\mathrm{msec}$ SOA, post hoc comparisons showed that performance on the three trial types was equivalent (average $=95 \%$ ).

The results for the second part of Experiment 2, when the target was followed by a masking stimulus, are shown in Figure 4. A comparison of Figures 3 and 4 shows that the presence of the masker was successful in reducing the

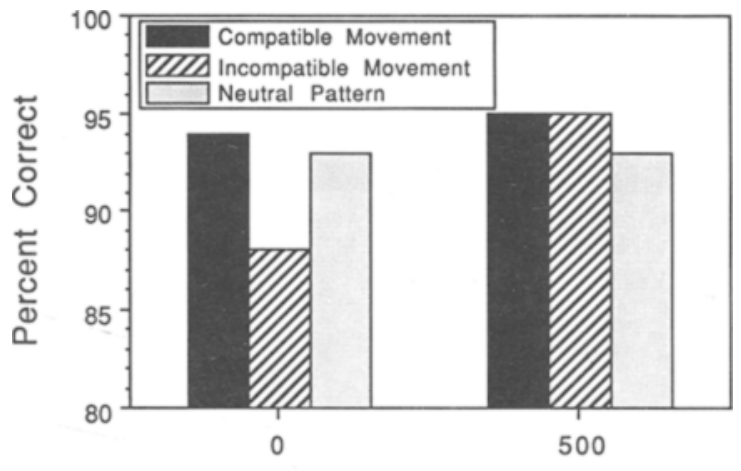

Stimulus Onset Asynchrony (in ms)

Figure 3. Percent correct movement identification for compatible-, incompatible-, and neutral-trial types at two SOAs.

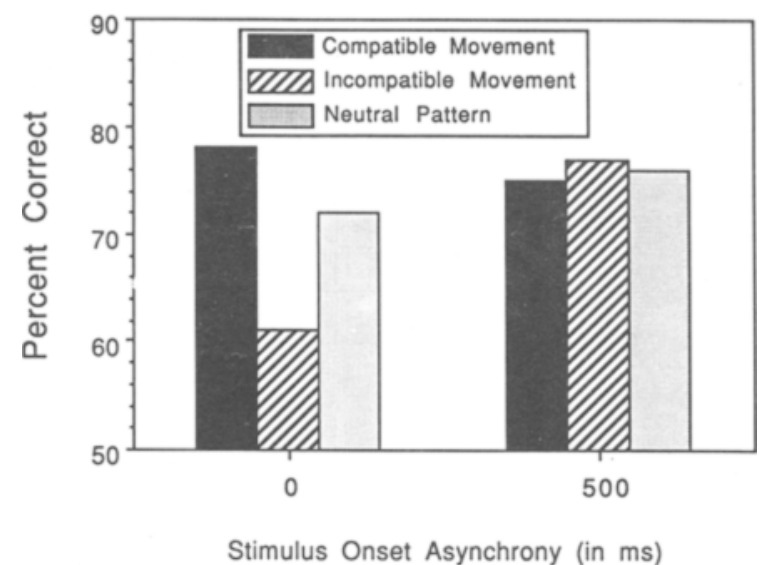

Figure 4. Percent correct movement identification for compatible-, incompatible-, and neutral-trial types at two SOAs. The target was followed by a masking stimulus.

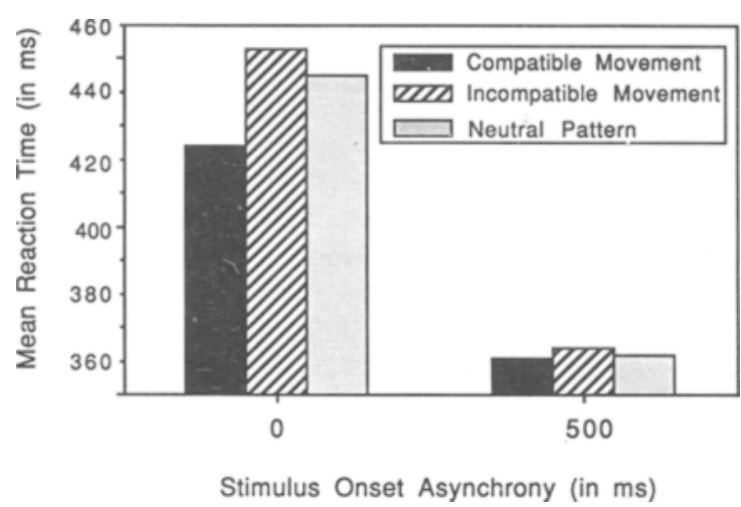

Figure 5. Mean latency (correct trials) for compatible-, incompatible-, and neutral-trial types at two SOAs.

overall level of performance. An analysis of variance revealed no main effect of SOA $[F(1,4)=2.07, p>.05]$, no main effect of trial type $[F(2,8)=3.64, p>.05]$, and a significant interaction between these two factors $[F(2,8)=4.74, p<.05]$. Post hoc comparisons revealed that at 0-msec SOA, performance was best when the nontarget moved in the same direction as the target $(78 \%)$, worst when the nontarget moved in the opposite direction from the target $(61 \%)$, and of intermediate value with the neutral pattern (72\%). At 500-msec SOA, performance on the three trial types was similar, with a mean of $76 \%$.

Reaction times. Figure 5 shows the mean reaction times (correct responses) for the three trial types as a function of SOA from the first part of Experiment 2. An analysis of variance showed a significant effect of SOA $[F(1,4)=78.81, p<.001]$, a significant effect of trial type $[F(2,8)=8.29, p<.02]$, and a significant interaction between these two factors $[F(2,8)=7.98, p<$ .02]. Post hoc comparisons showed that at $0-\mathrm{msec}$ SOA, reaction times were faster in the compatible-movement 
condition ( $424 \mathrm{msec}$ ) than in the incompatible-movement condition (453 msec). The difference, $29 \mathrm{msec}$, is of similar magnitude to that observed in Experiment 1. Reaction times with the neutral pattern tended to be faster $(445 \mathrm{msec})$ than when the nontarget moved in the opposite direction from the target $(453 \mathrm{msec})$, although this difference failed to reach an acceptable level of significance $(p>.05)$. At 500-msec SOA, reaction times were equivalent for the three trial types (average = $362 \mathrm{msec}$ ) and, overall, were significantly faster than at 0 - $\mathrm{msec}$ SOA (average $=440 \mathrm{msec}$ ), as observed in Experiment 1 .

These results provide evidence that the subjects were not simply, on occasion, attending to the wrong location. Focusing attention on the wrong location would, occasionally, lead the subject to begin to process the neutral (nonmoving) pattern. The subjects could either guess the direction of movement of the target on these trials or switch attention to the target location. The fact that reaction times with the neutral pattern fell between the compatible and incompatible conditions argues against the possibility that the subjects were attending, on occasion, to the wrong location. If the subjects guessed the direction of movement of the target on those trials when they were attending to the wrong location, we would have expected reaction times for the three trial types to be equivalent. If the subjects switched their attention quickly from the nontarget site to the target location, we would have expected reaction times with the neutral pattern to be slower than those obtained on compatible- and incompatiblemovement trials, but they were not. The evidence suggests that attention may be differentially weighted across adjacent fingers; however, regardless of instructions to the contrary, information about stimulation at a nontarget site appears to be processed.

The results of Experiment 2 replicate and extend those obtained in Experiment 1. In the first part of Experiment 2, accuracy was higher and reaction times were faster when the nontarget moved in the same direction as the target than when they moved in opposite directions. The reactiontime data suggest that there are both facilitatory and inhibitory components to these effects. Reaction times were fastest in the compatible-movement condition, slowest in the incompatible-movement condition, and of intermediate value with the neutral pattern. This suggestion is reinforced by the results from the second part of Experiment 2 when the target was followed by a masking stimulus: Accuracy was best when the target and the nontarget moved in the same direction, worst when they moved in opposite directions, and of intermediate value with the neutral pattern.

The statement that facilitation and inhibition may be involved in the effects reported here should be qualified. Compared with the neutral condition, performance was better when the nontarget and the target moved in the same direction than when they moved in opposite directions. One obvious question, however, is whether compatible movement across adjacent fingers (even though subjects are instructed to attend only to the target location) will lead to better performance than that obtained when only the target location is stimulated. The results of Essick and Whitsel (1988) showed that single-pattern performance was generally superior to the condition in which a nontarget location was also stimulated. In Experiment 3, we investigated this issue by including a condition in which the target was presented by itself.

\section{EXPERIMENT 3}

Two questions were addressed in Experiment 3. First, when subjects are identifying the direction of movement at a target location, is performance better, compared with a single-pattern condition, when a nontarget presented to a nonattended site moves in the same direction as the target? If presenting nothing to the nontarget location leads to target performance that is worse than that obtained in a compatible-movement condition, then this would imply that a true gain is achieved when adjacent fingers are stimulated in an identical fashion.

The second question addressed in Experiment 3 was, what effect does the spatial separation between the nontarget and the target have on movement identification? Investigations of tactile pattern masking have shown that presenting a target to the finger of one hand and a masker to the finger of the other hand results, essentially, in no masking (Craig, 1985a; Craig \& Xu, 1990). This result implies that subjects can restrict attention (or processing) to stimulation on one hand. If this is the case, then we would expect the effects observed in Experiments 1 and 2 to be reduced, or eliminated, when the nontarget is presented to the finger of one hand and the target is presented to a finger of the other hand.

\section{Method}

Five subjects participated in Experiment 3. The procedural details were identical to those of Experiment 2, with the following exceptions: First, there were six blocks of trials. On one block of 48 trials, single-pattern performance on the left index fingerpad was measured; on a second block of trials, single-pattern performance on the right index fingerpad was measured. On the remaining four blocks, two consisted of ipsilateral trials (the target was presented to the left index fingerpad and the nontarget was presented to the left middle fingerpad, as in Experiments 1 and 2), and two blocks consisted of contralateral trials (the target was presented to the right index fingerpad and the nontarget was presented to the left middle fingerpad). For the latter blocks of trials, the nontarget moved in the same direction as the target, in the opposite direction, or was the neutral pattern. In all conditions, the target pattern was followed by the masking stimulus used in Experiment 2. The subject indicated his/her responses by pressing one of two foot pedals. Each subject completed a total of nine experimental sessions.

\section{Results and Discussion}

The results are shown in Figure 6. A three-way repeated measures analysis of variance revealed no main effect of nontarget location (ipsilateral or contralateral) $[F(1,5)=$ $1.05, p>.05]$, no main effect of SOA $[F(1,5)=0.60$, $p>.05]$, and no main effect of trial type $[F(2,10)=$ 


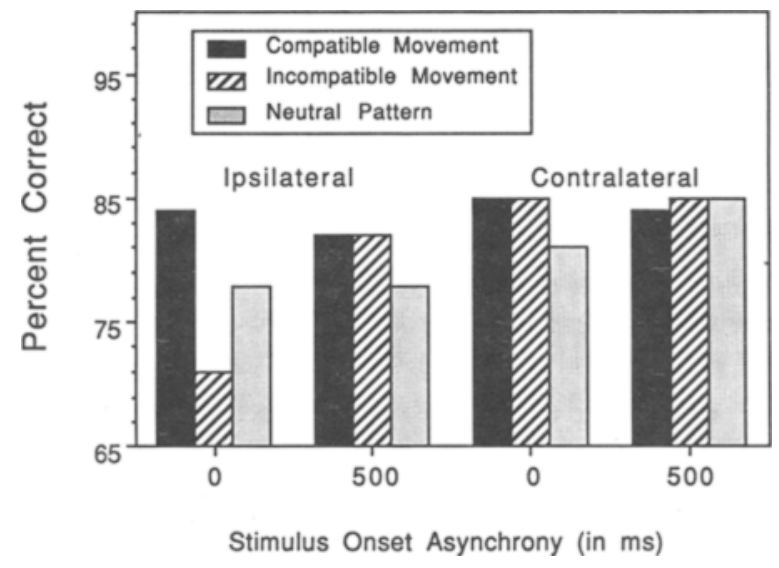

Figure 6. Percent correct movement identification for compatibie-, incompatible-, and neutral-trial types at two SOAs. The target and nontarget were presented to the same hand or to different hands.

$0.62, p>.05]$. There was a significant interaction between nontarget location and trial type $[F(2,10)=6.33$, $p<.02]$ and a significant interaction between all three factors $[F(2,10)=8.16, p<.01]$.

Post hoc comparisons showed that in the ipsilateral condition, performance was best when the nontarget and the target moved in the same direction (84\%), worst when the nontarget and the target moved in opposite directions $(71 \%)$, and of intermediate value with the neutral pattern (78\%). The minimum difference for an effect to be significant was $5.09 \%(p<.05)$. The results for the ipsilateral condition of Experiment 3 are almost identical to those obtained in Experiment 2. The exception is that overall performance was slightly better in Experiment 3 than in Experiment 2. In the contralateral condition, post hoc comparisons revealed no significant differences between the three trial types. Statistically, target performance was neither better nor worse when the nontarget (presented to the other hand) moved in the same or opposite direction as the target $(p>.05$, for all pairwise comparisons). Overall performance averaged $84 \%$.

When the target was presented by itself, average performance was $83 \%$. There was some indication that performance was better when the right index fingerpad was stimulated (85\%) than when the left index fingerpad was stimulated $(81 \%)$. This difference, however, was not statistically significant $(p>.05)$. Single-pattern performance was no better than that obtained in the compatiblemovement condition when the nontarget and target were presented ipsilaterally (83\% vs. $84 \%$, respectively). Thus, consistent movement across adjacent fingers did not result in better performance than that obtained when a single site was stimulated. This finding is consistent with a result reported in the masking literature, namely, that when a spatial masker is identical to a target and is presented to the same location, performance is identical to that obtained in the absence of a masker (Craig \& Evans, 1987). The fact that performance was worse with the neutral pattern, however, means that there is a cost incurred when a site adjacent to the target site is stimulated with a pattern that is different from the target.

The fact that performance was equivalent for all three trial types when the nontarget and the target were presented contralaterally implies that subjects can restrict their attention to stimulation on one hand. This result is consistent with the finding that very little, if any, interference is observed with spatial-pattern identification if the target is presented to the finger of one hand and the nontarget is presented to a finger on the other hand (Craig $\& \mathrm{Xu}, 1990)$. Noncorresponding sites-left, middle, and right index fingerpads-were tested in these measurements. A replication of these measurements with left index and right index fingerpads might reveal if patterns presented to corresponding sites are processed differently than are those presented to noncorresponding sites.

\section{GENERAL DISCUSSION}

The results of the present study support three major conclusions. First, when adjacent fingers are stimulated, subjects cannot restrict their attention to stimulation on a single finger. Processing capacity appears to be extended, without control, across adjacent fingers. Second, information about the direction of movement of tactile stimuli is processed across adjacent fingers even though subjects are explicitly instructed to attend only to the target location. Third, the fact that stimulating a nontarget location contralateral to the target site did not affect target performance leads to the conclusion that subjects can restrict attention to stimulation on a single hand.

The results of the present study are similar, in many respects, to those reported in the visual literature. A number of studies have shown that when a target letter is flanked by identical distractors (nontargets), responses are faster and more accurate than are responses in a control condition with neutral, irrelevant letters even though subjects are instructed to attend only to the target (B. A. Eriksen \& C. W. Eriksen, 1974; C. W. Eriksen \& Hoffman, 1973; C. W. Eriksen \& Schultz, 1979; Miller, 1982). Although a number of explanations of this effect have been proposed, it is clear that subjects cannot restrict processing to a single letter; several letters appear to be processed by the visual system simultaneously.

There has been much debate as to where in the perceptual process flanking distractors affect the ability to identify a visual target pattern (Estes, 1972, 1974; C. W. Eriksen \& Schultz, 1979; Miller, 1982; Shiffrin \& Geisler, 1973). A similar question can be raised about the locus of the effects observed in the present study. One finding that indicates that the present effects occur at an early stage of processing is that the neutral pattern, although not available as a response, resulted in poorer performance than was found in the compatible-movement condition (Experiments 1 and 2) or when the target was presented by itself (Experiment 3). By this view, interactions at an early stage of processing between inputs that are in close temporal 
and spatial proximity (and physically different) result in a degraded representation of the target (Evans, 1987; Evans \& Craig, 1986). The problem is that, although such an explanation might account for the fact that performance in the incompatible-movement and neutral conditions was worse overall than that obtained in the compatiblemovement condition, it fails to account for the difference between performance in the incompatible-movement and neutral conditions: Performance was consistently worse in the incompatible-movement condition.

An alternative explanation is that the effects reported here are the result of interactions at both early and late stages of processing. B. A. Eriksen and C. W. Eriksen (1974) have argued that information about sisual nontargets and targets accumulates simultaneously up to the level of response activation, and that nontargets may prime the incompatible response leading to a reduction in targetaccuracy and to an increase in the time taken to respond to the target (also see C. W. Eriksen \& Hoffman, 1973; C. W. Eriksen \& Schultz, 1979; Miller, 1982). Support for this view comes from the results of a study by C. W. Eriksen and Hoffman (1973). Subjects learned to move a response lever to the right if a pattern was, for example, the letter $H$ or the letter $K$, and to move the lever to the left if the target was either the letter $\mathbf{G}$ or the letter I. When target patterns were then flanked by distractors (e.g., H K H or G K G), little interference was observed when the distractors had the same learned response as the target. A significant amount of interference was observed, however, when the target and the distractors had different learned responses. Pilot work in our laboratory has shown that the effects reported here are also observed when tactile stimuli are moved in a distal-proximal fashion on the fingerpad. Thus, by using all four directions of movement (two assigned to one response, and the remaining two assigned to another response), the paradigm used by $C$. W. Eriksen and his colleagues could be used to assess the extent to which response competition is a factor involved in the identification of a tactile target in the presence of nontargets.

The finding that compatible movement at adjacent fingers leads to faster correct target responses, relative to incompatible movement, is similar, in some respects, to the finding in the visual literature that correct same responses to spatially identical stimuli are faster than correct different responses (Bamber, 1969; Krueger, 1978; Nickerson, 1965; Proctor, 1981). Indeed, C. W. Eriksen, O'Hara, and B. Eriksen (1982) have presented evidence that response competition, argued to be a factor involved in the deleterious effect of flanking distractors on the ability to identify a target stimulus, is also a factor involved in what has been termed the fast same effect (Proctor, 1981). If response competition is a factor involved in the effects reported herein, then we might expect same judgments of compatible movement across adjacent fingers to be faster than correct different judgments. Additional measurements will be required to address this issue.
The present results are consistent with measurements that have been conducted under the general rubric of masking. As discussed previously, the presentation of a nontarget stimulus (a masker) interferes with the identification of a tactile stimulus. Earlier studies have demonstrated that when the target and the masker are presented in sequence to the same location on the skin, the spatial characteristics of the target and the masker influence the amount of interference produced. Specifically, when the target patterns are letter-like, maskers composed of features from letters produce greater interference than do maskers without such features. Furthermore, no interference is seen when the target and the masker are spatially identical (Craig, 1982, 1983; Craig \& Evans, 1987; Evans \& Craig, 1986). These results indicate that subjects are unable to narrow their attention temporally to prevent processing of the masker's features. What the present study demonstrates is that a "masker" presented to a location separate from that of the target (on the same hand) is processed to the extent that at least some attributes of the pattern are registered.

The results of the present study have some implications for haptic information processing. For example, in Tadoma, one can certainly imagine situations in which users might encounter incompatible movements with adjacent fingers. Moreover, reaction-time differences of 30 to $40 \mathrm{msec}$ may well be important for processing rapidly varying speech information. In identifying objects by touch, it is, of course, less likely to have adjacent fingers encounter movement in opposite directions. If further studies show an inability to restrict attention for other stimulus dimensions, however, this would suggest that the effects observed in the present study are important factors in a wide range of information-processing tasks by the hand.

\section{REFERENCES}

BAmber, D. (1969). Reaction times and error rates for 'same' and 'different' judgments of multidimensional stimuli. Perception \& Psychophysics, 6, 169-174.

BERTELSON, P. (1967). The time course of preparation. Quarterly Joumal of Experimental Psychology, 19, 272-279.

Bliss, J. C., Katcher, M. H., Rogers, C. H., Shepard, R. P. (1970). Optical-to-tactile conversion for the blind. IEEE Transactions on Man-Machine Systems, MMS-11, 58-64.

Cholewiak, R. W., \& Craig, J. C. (1984). Vibrotactile pattern recognition and discrimination at several body sites. Perception \& Psychophysics, 35, 503-514.

Costanzo, R. M., GARDNer, E. P. (1980). A quantitative analysis of responses of direction-sensitive neurons in somatosensory cortex of alert monkeys. Journal of Neurophysiology, 43, 1319-1341.

CRAIG, J. C. (1974). Vibrotactile difference thresholds for intensity and the effect of a masking stimulus. Perception \& Psychophysics, 15, 123-127.

CRAIG, J. C. (1980). Modes of vibrotactile pattern generation. Joumal of Experimental Psychology: Human Perception \& Performance, 6 , 151-166.

CraiG, J. C. (1982). Vibrotactile masking: A comparison of energy and pattern maskers. Perception \& Psychophysics, 31, 523-529.

CRAIG, J. C. (1983). The role of onset in the perception of sequentially 
presented vibrotactile patterns. Perception \& Psychophysics, 34, 421-432.

Craig, J. C. (1985a). Attending to two fingers: Two hands are better than one. Perception \& Psychophysics, 38, 496-511.

CraIG, J. C. (1985b). Tactile pattern perception and its perturbations. Journal of the Acoustical Society of America, 77, 238-246.

Craig, J. C., \& Evans, P. M. (1987). Vibrotactile masking and the persistence of tactual features. Perception \& Psychophysics, 42, 309-317.

Craig, J. C., \& Xu, B. (1990). Temporal order and tactile patterns. Perception \& Psychophysics, 47, 22-34.

Egan, J. P., Greenberg, G. E., \& Schulman, A. J. (1961). Interval of time uncertainty in auditory detection. Journal of the Acoustical Society of America, 33, 771-778.

ERIKSEN, B. A., ERIKSEN, C. W. (1974). Effects of noise letters upon the identification of a target letter in a nonsearch task. Perception \& Psychophysics, 16, 143-149.

Eriksen, C. W., Hoffman, J. E. (1973). The extent of processing noise elements during selective encoding from visual displays. Perception \& Psychophysics, 14, 155-160.

Eriksen, C. W., O'HARA, W. P., \& ErIKSEN, B. (1982). Response competition effects in same-different judgments. Perception \& Psychophysics, 32, 261-270.

ERIKSEN, C. W., \& SChultz, D. W. (1979). Information processing in visual search: A continuous flow conception and experimental results. Perception \& Psychophysics, 25, 249-263.

Essick, G. K., \& WhITSEL, B. L. (1988). The capacity of human subjects to process directional information provided at two skin sites. Somatosensory \& Motor Research, 6, 1-20.

EsTES, W. K. (1972). Interactions of signal and background variables in visual processing. Perception \& Psychophysics, 12, 278-286.

EsTES, W. K. (1974). Redundancy of noise elements and signals in visual detection of letters. Perception \& Psychophysics, 16, 53-60.

Evans, P. M. (1987). Vibrotactile masking: Temporal integration, persistence, and the strengths of representations. Perception \& Psychophysics, 42, 515-525.

Evans, P. M., \& CraIG, J. C. (1986). Temporal integration and vibrotactile backward masking. Journal of Experimental Psychology: Human Perception \& Performance, 12, 160-168.

GARDNER, E. P. (1984). Cortical neuronal mechanisms underlying the perception of motion across the skin. In C. Von Euler, O. Franzen, U. Lindblom, \& D. Ottoson (Eds.), Somatosensory mechanisms (pp. 93-112). London: Macmillan.

Gardner, E. P., Hamalainen, H. A., Palmer, E. P., \& Warren, S. (1989). Touching the outside world: Representation of motion and direction within the primary somatosensory cortex. In J. S. Lund (Ed.), Sensory processing in the mammalian brain: Neural substrates and experimental strategies (pp. 49-66). New York: Oxford University Press.

Gardner, E. P., \& Palmer, C. I. (1989). Simulation of motion on the skin: I. Receptive fields and temporal frequency coding by cutaneous mechanoreceptors of Optacon pulses delivered to the hand. Journal of Neurophysiology, 62, 1437-1460.

Gardner, E. P., \& Palmer, C. I. (1990). Simulation of motion on the skin: III. Mechanisms used by rapidly adapting cutaneous mechanoreceptors in the primate hand for spatiotemporal resolution and twopoint discrimination. Journal of Neurophysiology, 63, 841-859.
Geldard, F. A., \& Sherrick, C. E. (1965). Multiple cutaneous stimulation: The discrimination of vibratory patterns. Journal of the Acoustical Society, 37, 797-801.

GiLSON, R. D. (1969). Vibrotactile masking: Some spatial and temporal aspects. Perception \& Psychophysics, 5, 176-180.

Kirman, J. H. (1974). Tactile apparent movement: The effects of interstimulus onset interval and stimulus duration. Perception \& Psychophysics, 15, 1-6.

KIRMan, J. H. (1983). Tactile apparent movement: The effects of shape and type of motion. Perception \& Psychophysics, 34, 96-102.

Krueger, L. E. (1978). A theory of perceptual matching. Psychological Review, 85, 278-304.

Miller, J. (1982). Effects of noise letters on decisions: Discrete or continuous flow of information? Perception \& Psychophysics, 31, 227-236.

Morley, J. W., \&oodwin, A. W. (1987). Sinusoidal movement of a grating across the monkey's fingerpad: Temporal patterns of afferent fiber responses. Journal of Neuroscience, 7, 2181-2191.

Nickerson, R. S. (1965). Response times for "same"'-"different" judgments. Perceptual \& Motor Skills, 20, 15-18.

POSNER, M. I. (1980). Orienting of attention. Quarterly Journal of Experimental Psychology, 32, 3-25.

Posner, M. I., \& Boles, S. J. (1971). Components of attention. Psychological Review, 78, 391-408.

Proctor, R. W. (1981). A unified theory for matching-task phenomena. Psychological Review, 88, 291-326.

Reed, C. M., Durlach, N. I., Braida, L. D. (1982). Research on tactile communication of speech: A review. American Speech Language \& Hearing Association (ASHA) Monograph, 20, 1-23.

SHERRICK, C. E. (1964). Effects of double simultaneous stimulation of the skin. American Journal of Psychology, 77, 42-53.

ShERRICK, C. E. (1968). Studies of apparent tactual movement. In D. R. Kenshalo (Ed.), The skin senses (pp. 331-343). Springfield, IL: Charles C. Thomas.

Sherrick, C. E., Cholewiak, R. W. (1986). Cutaneous sensitivity. In K. R. Boff, L. Kaufman, \& J. P. Thomas (Eds.), Handbook of perception and human performance: Sensory processes and perception. New York: Wiley.

SHERRICK, C. E., Rogers, R. (1966). Apparent haptic movement. Perception \& Psychophysics, 1, 175-180.

Shiffrin, R. M., \& Geisler, W. A. (1973). Visual recognition in a theory of information processing. In R. L. Solso (Ed.), Contemporary issues in cognitive psychology: The Loyola symposium. Washington, DC: Winston.

Warren, S., Hamalainen, H., \& Gardner, E. P. (1986). Objective classification of motion- and direction-sensitive neurons in primary somatosensory cortex of awake monkeys. Joumal of Neurophysiology, 56, 598-622.

WeISEnBerger, J. M. (1981). Tactile pattern similarity. Unpublished doctoral dissertation, Indiana University, Bloomington, IN.

Whitsel, B. L., Roppolo, J. R., Werner, G. (1972). Cortical information processing of stimulus motion on primate skin. Journal of Neurophysiology, 35, 691-717.

(Manuscript received August 31, 1990; revision accepted for publication December 3, 1990.) 